Results 17 patients were enrolled, 9 men and 8 women, aged 34 to 76 , with various stages of AVN (from stage 1 to 4). Antithrombin III deficiency was diagnosed in a woman. Resistance to activated protein $\mathrm{C}$ was found in another woman. Hyperhomocysteinemia was identified in 6 patients: two women (associated with antiphospholipid antibodies in one case), and 4 men. A lupus anticoagulant was found in one man and one woman. Two other patients were found to be homozygous to methyl-tetrahydrofolate reductase (MTHFR) mutation, condition which leads to a susceptibility to hyperhomocysteinemia.

Conclusion 59\% of our patients with AVN were found to have a thrombophilic disorder. We suggest that such a disorder may precipitate thrombosis when added to other risk factors. Among these thrombophilic disorders, hyperhomocysteinemia seemed to be the most frequent factor associated with AVN. If hyperhomocysteinemia is confirmed to be involved in AVN, these results should be of special interest in prevention of recurrences, as hyperhomocysteinemia can be corrected by folic acid, B6 and B12 supplementation.

\section{SAT0105 LOSARTAN BUT NOT IRBESARTAN REDUCES SERUM URIC ACID IN HYPERTENSIVE PATIENTS WITH GOUT}

G Wuerzner, A Chioléro, M Maillard, CL Stubi-Fallab, M Burnier, CA Gerster. Hypertension, Lausanne University Hospital, Lausanne, Switzerland

\subsection{6/annrheumdis-2001.488}

Background Losartan is the only angiotensin II receptor antagonist with uricosuric properties and has been shown to decrease serum uric acid (SUA) levels in normal subjects as well as in hypertensive patients.

Objectives To assess and to compare the effects of losartan and irbesartan on serum uric acid in hypertensive patients with gout. Methods Prospective, randomised, double-blind, cross-over study preceded by a three weeks run-in period with enalapril $20 \mathrm{mg}$ od. During the first four weeks, patients received a morning dose of either losartan $50 \mathrm{mg}$ or irbesartan $150 \mathrm{mg}$ and a evening dose of placebo. The dose was than increased to losartan $50 \mathrm{mg}$ bid or irbesartan bid. The losartan and the irbesartan phases were separated by three weeks of treatment with enalapril $20 \mathrm{mg}$ od.

All drugs were provided in an electronic pill container allowing to monitor compliance (MEMS system).

Results Thirteen male hypertensive (office blood pressure > $140 / 90 \mathrm{mmHg}$ or under antihypertensive therapy) and hyperuricemic (SUA over $420 \mu \mathrm{mol} / \mathrm{L}$ or over $7.1 \mathrm{~g} / \mathrm{dL}$, without any hypouricemic agents) patients completed this study.

The changes in blood pressure induced by losartan and irbesartan were comparable. In contrast to irbesartan which had no effect on SUA, losartan (50 mg od) decreased SUA significantly from $538 \pm 26 \mu \mathrm{mol} / \mathrm{L}$ to $491 \pm 20 \mu \mathrm{mol} / \mathrm{L}(\mathrm{p}<0.01$ ) and to $484 \pm 25 \mu \mathrm{mol} / \mathrm{L}$ at $50 \mathrm{mg}$ bid. During the first $4 \mathrm{~h}$ after drug intake, the first dose of losartan increased the urinary uric acid/ creatinine ratio when compared with irbesartan $(0.525 \pm 0.071$ vs $0.358 \pm 0.045, \mathrm{p}=0.019)$. This increase was still present at week $4(0.485 \pm 0.085$ vs $0.331 \pm 0.057, \mathrm{p}<0.01)$ but was not found at week 8 when patients received a bid regimen $(0.316 \pm 0.043$ vs $0.331 \pm 0.029, p=n s)$. The frequency of acute gout episods did not differ between treatments. The monitoring of compliance showed that the adherence to the morning dose was good $(89.2 \pm 2.8 \%)$ and significantly greater than that to the evening dose $(78.9 \pm 3.1 \%, \mathrm{p}<0.001)$.
Conclusion These results demonstrate the potential benefits of using losartan in hypertensive patients with hyperuricemia and gout. They also suggest that losartan-treated patients reach a new uric acid steady-state during a sustained administration ( $>1$ month). Hence, the uricosuric effect tends to decrease with time as SUA is reduced. Increasing the dose of losartan to $50 \mathrm{mg}$ bid does not appear to induce a further decrease in serum uric acid.

\section{Pediatric rheumatology}

\section{AB0158 MUSCULOSKELETAL PAIN IN CHILDREN AND ADOLESCENTS}

MM Costa, P Nero, E Branco, J Branco. Rheumatology, Egas Moniz, Lisbon, Portugal

10.1136/annrheumdis-2001.489

\section{Background}

Objectives The purpose of this study was the determination of the frequency and consequence of musculoskeletal pain in urban children and adolescents.

Methods This study was performed in unselected population of two urban schools. Two Rheumatologists visited 479 children (216 boys and 263 girls) in their school. Mean age was $11+2.4$ years, range 6-17 yr. The survey included a detailed interview on the basis of a standardised questionnaire and physical examination. The severity of their pain was assessed by visual analogue scale and a subjective disability index.

Results About 30.3 percent (145/479) of cases had musculoskeletal pain. The pain was located at lower extremity in $74 \%$ of children. Thirty-one case $(21.4 \%)$ had spinal pain and 19 (13.1\%) had upper extremity pain. The severity of their pain, by visual analogue scale, had a mean $3.2+1.8$ (range $0.1-8$ ) and $3 / 4$ of cases had disability. Pain relapses weekly in $38 \%$ and persists part of a day in $74 \%$. Twenty eight percent (40/145) consulted their physician and 31 children consumed drugs. The physical activity and schoolbag carriage was associated with pain in $61 \%$ $(89 / 145)$ of cases.

There were no statistically significant demographic differences among cases with and without musculoskeletal pain, except for sex, as is shown in the Table 1 :

\begin{tabular}{|c|c|c|c|c|c|}
\hline & Age & Sex* & Sports & Weight & Height \\
\hline Pain & $10 \pm 2.2$ & $\mathrm{~F}=93 ; \mathrm{M}=52$ & 43 & $43.3 \pm 14.4$ & $144.6 \pm 13.3$ \\
\hline No pain & $11 \pm 2.5$ & $F=170 ; M=164$ & 107 & $42.9 \pm 14.5$ & $145.2 \pm 14.6$ \\
\hline
\end{tabular}

Conclusion In our population lower extremity pain was more prevalent. It had a relapsing character and determines disability and consumption of medical services. The relationship with physical activity (practice of sports) was referred by children and was evaluated in other study.

\section{AB0159 JOINT HYPERMOBILITY AND MUSCULOSKELETAL PAIN}

MM Costa, P Nero, E Branco, J Branco. Rheumatology, Egas Moniz, Lisbon, Portugal 


\section{Background}

Objectives The aim of this study was analyse the frequency of joint hypermobility in urban schoolchildren and association with musculoskeletal pain.

Methods The modified criteria of Cartier and Wilkinson for joint hypermobility was applied, by two Rheumatologists, on 479 schoolchildren (263 female and 216 male). Mean age was $11+2.4$ years, range $6-17$ years. The population was $92 \%$ Caucasian. All children answered a questionnaire for musculoskeletal pain.

Results Forty one percent had one of the five positive test manoeuvres for joint hypermobility. Only one child had 3 positive test manoeuvres, 20 had two positive test and 175 had one positive test manoeuvres (mean $1.1+0.3$ ). Passive apposition of the thumbs to the flexor aspects of the forearm occurred in 168 cases.

Musculoskeletal pain occurred in 32\% of children, without relationship of pain and hypermobility in the same joint.

Presence of pain was no statistically significant among cases with and without hypermobility.

Physical activity was no associated with pain in hypermobility joint.

Conclusion Hypermobility syndrome was rare in our population. Passive apposition of the thumbs to the flexor aspects of the forearm was the most frequent positive manover. Joint hypermobility was no related with musculoskeletal pain. Physical activity was no a risk factor to pain in joint with hyperlaxity.

\section{AB0160 THE INFLUENCE OF DIFFERENT KINDS OF THERAPHY ON OXIDATIVE-ANTIOXIDATIVE BALANCE IN CHILDREN WITH JUVENILE IDIOPATHIC ARTHRITIS/JIA/}

J Postêpski, V Opoka-Winiarska, E Tuszkiewicz-Misztal, M Wawrzyszuk. Department of Paediatrics, Pulmonary Diseases and Rheumatology, Medical University, Lublin, Poland

\subsection{6/annrheumdis-2001.491}

Background The aim of this study was to investigate the influence of different kinds of theraphy on oxidative-antioxidative balance in children with rheumatoid idiopatic arthritis.

Objectives In our study the intensity of peroxide lipid oxidation was calculated by the contents of malonic dialdehyde (MDA) in plasma. At the same time antioxidant activity was evaluated. We measured the content of vitamin E (Vit. E) in plasma, the total antioxidant status (TAS), as well as the activity of glutathion peroxidase (GPX) and superoxide dismutase (SOD).

In our study we examined 39 children with JIA aged 4-18 years and 27 healthy subjects aged $4-16$ years.

8 patients were treated with glicocorticosteroids administered $1-2 \mathrm{mg} / \mathrm{kg} / 24 \mathrm{~h}$ in relation to the prednisone standard. 8 children received Methtrexatein the dose of $10-15 \mathrm{mg} / \mathrm{m}^{2} /$ week. 9 children were treated with Sulphasalazine in the dose of 20-40 $\mathrm{mg} / \mathrm{kg} / 24$ h. 14 children were treated with non-steroid antiinflammatory agents (naproxen $10 \mathrm{mg} / \mathrm{kg} / 24 \mathrm{~h}$ ). The examination was performed 4-6 weeks after the beginning of the treatment. The results obtained after the treatment were compared with those obtained before the treatment and those in the control group.

Methods We used colorymetric and fluorometric methods.

Results The level of MDA before the treatment, i.e. 2,32 $\pm 0,86$ $\mathrm{nM} / \mathrm{ml}$, was significantly higher than that in the control group, i. e. $1,32 \pm 0,38 \mathrm{nM} / \mathrm{ml}(\mathrm{p}<0,05)$. After the treatment with Mtx, Sulphasalazine and non-steroid anti-inflammatory agents, the values of MDA were still significantly higher than those in the control group and equalled, respectively, 2,32 $\pm 0,71 \mathrm{nM} /$ $\mathrm{ml}, 2,14 \pm 0,1 \mathrm{nM} / \mathrm{ml}$, and 2,14 $\pm 0,1 \mathrm{nM} / \mathrm{ml}(\mathrm{p}<0,05)$. After the treatment with glicocorticosteroids, the values of MDA approximated to those in the control group and averaged 1,72 $\pm 0,17 \mathrm{nM} / \mathrm{ml}(\mathrm{p}<0,05)$. Before the treatment, the activity of GPX was significantly lower than those in the control group $(4,75 \pm 2,59 \mathrm{U} / \mathrm{ml}$ vs $7,06 \pm 1,99 \mathrm{U} / \mathrm{ml}(\mathrm{p}<0,05))$. The values of the other parameters did not appear to depend on the treatment.

Conclusion 1. Our results confirmed the existence of oxidative stress in children with juvenile idiophatic arthritis. 2. The strongest inhibitory effect on peroxide lipid oxidation is exerted by glicocorticosteroids, which conforms to their strongest antiinflammatory activity. No significant influence of non-steroid anti-inflammatory agents on peroxide lipid oxidation was observed, despite their generally-acknowledged, weak antioxidative activity. No influence of Mtx and Sulphasalazine on peroxide lipid oxidation was observed in the period of examination.

\section{AB0161 CLINICAL AND SEROLOGIC CHARACTERISATION OF 72 JUVENILE IDIOPATHIC ARTHRITIS PORTUGUESE PATIENTS}

C Resende, H Canhão, W Castelão, JE Fonseca, JC Teixeira Costa, JA Pereira Silva, M Viana Queiroz. Rheumatology Unit, Santa Maria Hospital, Lisbon, Portugal

\subsection{6/annrheumdis-2001.492}

Background Juvenile Idiopathic Arthritis (JIA) is a heterogeneous group of systemic inflammatory disorders affecting children below the age of 16 years.

Objectives

Methods We have used the ILAR revised classification criteria for JIA in order to evaluate the clinical patterns of disease of 72 patients regularly followed in our Unit.

Results 72 children with the diagnosis of JIA are being regularly followed: $41(57 \%)$ females and 31 (43\%) males. The mean age of diagnosis was $6.6 \pm 4.9$ years (females) and $8.0 \pm 4.5$ years (males). The mean follow-up period was 5,44 \pm 4.0 years, with a mean disease duration of $6,31 \pm 4.6$ years. Patients were classified in JIA subtypes: systemic $-16(22,2 \%)$; polyarthritis -6 $(8,3 \%)$; oligoarthritis - $35(48,6 \%)$ : extended $-9(12,5 \%)$ and persistent ? $26(36,1 \%)$; enthesitis ? $13(18,0 \%)$; psoriatic arthritis ? $2(2,7 \%)$. The knee was the most commonly involved joint in all subtypes: $77.7 \%$ of the extended oligoarthritis patients, $92 \%$ of the persistent oligoarthritis, $75 \%$ of the systemic arthritis, $83.3 \%$ of the polyarthritis, $100 \%$ of the psoriatic arthritis and $61.5 \%$ of the enthesitis related arthritis patients. The second most affected joint was the elbow in extended oligoarthritis (66.6\%), the hand in persistent oligoarthritis (30.7\%), the wrist in systemic arthritis (50\%); the hand and wrist in polyarthritis $(83.3 \%)$ and psoriatic arthritis (100\%), the ankle and hip in enthesitis related arthritis $(53.8 \%$ and $46.1 \%)$. Antinuclear antibodies (ANA) were presented in 19 (26.3\%) children: 4 (44.4\%) extended oligoarthritis patients; 11 (42.3\%) persistent oligoarthritis patients; $2(12.5 \%)$ systemic arthritis patients and 2 (15.3\%) enthesitis related arthritis. Rheumatoid factor (FR) was only present in $3(50 \%)$ children with polyarthritis and HLAB27 was only found in $8(66.6 \%)$ children with enthesitis related arthritis. Uveitis affected $10(13.8 \%)$ children: 6 (23.1\%) with persistent oligoarthritis, $2(22.2 \%)$ with extended oligoarthritis, $1(6.2 \%)$ with systemic arthritis and 1 (7.6\%) with enthesitis 